\title{
Gender differences in sexual attraction and moral judgement: research with artificial face models.
}

\begin{abstract}
Sexual attraction in humans is influenced by cultural or moral factors and some gender differences can emerge in this complex interaction. A previous study (Author, 2015) found that men dissociate sexual attraction from moral judgement more than women do. Two experiments consisting of giving attractiveness ratings to photos of real opposite-sex individuals showed that men, compared to women, were significantly less influenced by the moral valence of a description about the person shown in each photo.

There is evidence of some processing differences between real and artificial computer-generated faces. The present study tests the robustness of Author's findings and extends the research to an experimental design using artificial face models as stimuli. A sample of 88 young adults (61 females, 27 males, average age 19.32, SD = 2.38) rated the attractiveness of eighty $3 D$ artificial face models generated with the FaceGen Modeller 3.5 software. Each face model was paired with a "good" and a "bad" (from a moral point of view) sentence depicting a quality or activity of the person represented in the model (e.g., s/he is an altruistic nurse in Africa vs. s/he is a prominent drug-dealer). Results were in line with the previous findings and showed that, with artificial faces as well, sexual attraction is less influenced by morality in men than in women. This gender difference is consistent with an evolutionary perspective on human sexuality.
\end{abstract}

Keywords: Gender Differences; Sexual attraction; Social Perception; Morality; Evolution. 
Physical appearance (and especially the face) is the most accessible personal information in social interactions. The "what is beautiful is good" stereotype assumes that attractive people have a set of positive qualities. But what about the opposite idea, "what is good is beautiful"? Gross and Crofton (1977) found evidence that the stereotypical relationship between beauty and goodness could be bidirectional, and it "may operate in the opposite direction such that the more we like and value people, the more physically attractive they appear to us" (p. 86). Further research has obtained additional evidence that personality information can influence perceptions of physical attractiveness (Kniffin \& Wilson, 2004; Lewandowski, Aron, \& Gee, 2007; Zhang, Kong, Zhong, \& Kou, 2014).

In a previous study, one of the authors found an important gender difference in the way morality can influence physical attraction between opposite-sex individuals (Author, 2015). Specifically, Author observed that men separate sexual attraction from moral judgements significantly more than women do. In two experiments, participants were presented with photographs of real opposite-sex persons and asked to rate them on an attractiveness scale. Each photograph was duplicated, and each copy was paired with a "good" or "bad" sentence about the person displayed (e.g., s/he is a defender of human rights in an NGO vs. s/he belongs to a terrorist group). Data showed a significant and strong interaction between the participant's gender and the sentence condition because the attractiveness ratings given by men were much less affected by the "bad" sentences than the ratings given by women. 
Author's (2015) results suggested that male attraction at first sight to a strange woman seems relatively less permeable to moral factors (and probably to other nonphysical factors) than female attraction to a strange man. This gender difference is coherent with other differences reported in the scientific literature: men generally respond more to sexual stimuli than women (Buss, 2007), especially when the stimuli are visual (Rupp \& Wallen, 2008), and neural activation of some brain structures such as the amygdala and hypothalamus reflects this divergence between human males and females (Hamann, Herman, Nolan, \& Wallen, 2004). Compared to women, men tend to give more importance to their partner's physical attractiveness (Furnham, 2009), and typically report stronger sex drive or sexual motivation (Lippa, 2009).

On the other hand, extensive cross-cultural studies about short-term mating disclose a universal pattern: it seems that men are less selective, have more desire for sexual variety, and tend to seek short-term mateships more actively than women (Schmitt, 2005; Schmitt et al., 2003). A pattern also observed in countries like Norway, a nation with a high rate in gender empowerment terms (as indexed by the United Nations) (Kennair, Schmitt, Fjeldavli, \& Harlem, 2009). Obviously, this type of gender difference can obey to a wide variety of reasons. However, an important number of authors consider that the cross-cultural universality of this pattern reveals a biological root and it is well-predicted from an evolutionary approach of human sexuality (Buss, 2007; Buss \& Schmitt, 1993; but see Eagly \& Wood, 1999). From this point of view, a clear asymmetry between men and women in biological parental investment (internal fertilization, gestation and lactation) also favors evolutionary asymmetry in mating 
strategies (human females would be more selective and would prefer males who are willing to consider parental investment).

The experimental paradigm used by Author (2015) (comparing attractiveness ratings received by the same faces when paired with "good" vs. "bad" moral content) is a methodology applied to these specific variables (sexual attraction, morality) for the first time. Thus, at the moment, Author (2015) is the single study that has addressed the issue with this paradigm. Contemporary psychology, along with other sciences, is living a certain crisis (see Science, 2015), and there is an overall concern about reproducibility and robustness of experimental results, particularly in social psychology. In the present study, we tested the robustness of the experimental paradigm used by Author (2015) and the robustness of the findings, extending the research to another type of stimuli (high-quality artificial faces) that are presumably processed differently. On the other hand, the study has relevance by itself since high-quality artificial faces are increasingly frequent in movies, video games, computer interfaces and other media (Balas \& Pacella, 2015), and the results may have implications for the fields of robotics and humancomputer interaction (see p.e., Swiderska, Krumhuber, \& Kappas, 2013, about out-group effects in real and artificial faces).

The experimental stimuli used in Author's (2015) study were photographs of real, unknown people selected from the Internet (Google Images) and mixed with some photographs of a celebrity or well-known person (included as filler stimuli). The purpose of the present paper was to extend Author's finding using artificial face models as stimuli. There is evidence of some processing differences between artificial computergenerated faces and photos of real faces, both at the cognitive (Balas \& Pacella, 2015; 
Carlson, Gronlund, Weatherford, \& Carlson, 2012; Kätsyri \& Sams, 2008) and neural levels (Mühlberger et al., 2009; Wheatley, Weinberg, Looser, Moran, \& Hajcak, 2011). Artificial faces seem to be harder to recognize and remember, and some basic emotions stemming from this type of stimuli are identified and processed differently (Ehrlich, Schiano, \& Sheridan, 2000; Kätsyri \& Sams, 2008). In the present study, we intend to test the robustness of the gender differences found in Author (2015) by extending the same experimental design to computer-generated virtual 3D face models.

Hypothesis 1. Given Author's (2015) findings, artificial faces paired with a "bad" (from a moral point of view) sentence will be rated as less attractive than the same faces paired with a "good" sentence.

Hypothesis 2. Crucially, the attractiveness-rating difference between artificial faces paired with "good" versus "bad" sentences will be greater for the female participants than for the males. That is, rating data will show an interaction between the participant's gender and the sentence condition.

\section{METHOD}

Participants.

Eighty-eight undergraduate students (61 females, 27 males) from the University XXXXX participated in this study, ranging in age from 18 to 27 years ( $M=19.32$; $S D=2.38$ ). All of them volunteered in exchange for course credits. The research conformed to the American Psychological Association's Ethical Principles and Code of Conduct for Psychologists.

Stimuli. 
The experimental stimuli consisted of 80 realistic 3D artificial face models generated with the FaceGen Modeller 3.5 software (Singular Inversions, 2010): 40 were of males and 40 of females, both of diverse ethnicities. FaceGen is a widely used program in research on face perception (e.g. Oosterhof \& Todorov, 2008), and it includes statistical algorithms developed from 3D laser scans of human faces. It can generate 3D virtual faces at random, modifiable on sixty-one parameters grouped into 10 feature categories (brow, cheek, mouth, nose, jaw, etc.) and four controls for apparent age, gender, asymmetry, and racial origin. Once a model has been generated, FaceGen makes it possible to select or create a skin texture overlay.

All the faces created for this experiment were without hair or any kind of accessories. They included a skin texture and displayed a neutral expression in the same default 3D position: yaw angle: $20.05^{\circ}$ and pitch angle: $0.00^{\circ}$, (see two examples in Fig. 1). We used two identical copies of each face model. One copy was paired with a "good" sentence about the person displayed or his/her activity (e.g., s/he is an altruistic nurse in Africa), and the other copy was paired with a "bad" sentence about the person displayed or his/her activity (e.g. s/he is a prominent drug-dealer). Each sentence was headed by a fictitious proper name. Sentences were selected from the pool used in Author $(2015)^{1}$.

In order to make the descriptions more realistic, 30 additional artificial face models (15 of men and 15 of women) were included as filler stimuli, most of them based on celebrities, politicians, or well-known people (FaceGen can create virtual 3D face models based on photographs of real people). Each filler was paired with a true 
description (e.g., a computer model of Angela Merkel was paired with the sentence: "Angela Merkel is the current head of government of Germany", see Figure 2).

For each face gender, two lists of 55 stimuli (40 experimental +15 fillers) were constructed to include one copy of each face model on a different list. Each list had the same number of experimental "good" and "bad" sentences. Each participant was presented with only one list, and so none of the participants saw more than one version of a given face model.

\section{Procedure}

Each participant was randomly assigned to one of the two stimulus lists of the opposite sex and completed the experiment individually online in the university intranet (virtual classroom). Research on face perception has shown that laboratory and online studies produce equivalent results (e.g., Lefevre, Ewbank, Calder, Von dem Hagen, \& Perrett, 2013).

The instructions and procedure were similar to those of Author's (2015) study. Participants wrote their name and demographic data, and received the following instructions (in Spanish): "We are preparing an experiment to study the keys of physical attractiveness in men and women. Beforehand, we need to have stimuli with varying degrees of attractiveness and this experiment is designed to study the attractiveness of each stimulus. In each trial, you will see the image of a virtual 3D face model created by computer and based on a real man [woman] which has been selected from media or the Internet. These men [women] are on the media or Internet in connection with any news related to them. Some are better known than others. You have to see the photo and 
read who he/she is. Next you must indicate to what degree you find this man [woman] sexually attractive from a physical point of view".

Each trial displayed a face $(6 \times 6 \mathrm{~cm})$ on the computer screen, with the corresponding sentence below the image. Participants were instructed to look at the image and read the description, and subsequently rate the physical attractiveness of the face on a 7-point scale from 1- not at all attractive to 7- very attractive. Several reminders appeared during the experimental session, highlighting the importance of looking at and reading the material before rating each stimulus.

\section{RESULTS AND DISCUSSION}

The attractiveness ratings given by men to artificial female faces paired with a "good" sentence yielded $M=3.03(S D=0.63), 95 \% \mathrm{Cl}[2.78,3.28]$, and the same faces paired with "bad" sentences yielded $M=2.70(S D=0.67), 95 \% \mathrm{Cl}[2.44,2.97]$. The attractiveness ratings given by women to artificial male faces paired with a "good" sentence yielded $M=2.84(S D=0.77), 95 \% \mathrm{Cl}[2.64,3.04]$, and the same faces paired with a "bad" sentence yielded $M=2.09$ ( $S D=0.66), 95 \% \mathrm{Cl}[1.92,2.26]$ (see Table 1).

A two-way analysis of variance (ANOVA) was carried out, including the sentence's moral type ("good", "bad") as within-participants factor, and the gender of the participants (men, women) as between-participants factor (see Table 2). Separate analyses were performed, with participants $\left(F_{1}\right)$ and items $\left(F_{2}\right)$ as the random variables. The gender factor was significant because the overall mean rating by men (2.87) was significantly higher than the overall mean rating by women (2.47). Thus, the virtual male faces created at random by the FaceGender software were probably, in general terms, somewhat less attractive to the women than the virtual female faces were to men. 
As expected (Hypothesis 1), the sentence's moral type ("good", "bad") was significant and showed a large effect size because the "bad" sentences lowered the attractiveness scores of the virtual faces (-0.54 points). Crucially, the interaction between the sentence's moral type and the gender of the participants was clearly significant because the effect of morality on the attractiveness ratings was greater for women than for men (Hypothesis 2). Specifically, the rating difference between "good" vs. "bad" conditions was $M=0.75(S D=0.73), 95 \% \mathrm{Cl}[0.56,0.94]$ for women, and $M=$ $0.33(S D=0.66), 95 \% \mathrm{Cl}[0.07,0.59]$ for men, (both means significantly different, $\mathrm{t}(86)=$ 2.54, $\mathrm{p}=.013$; Cohen's $d=0.60$ ).

There is evidence of some differences in the cognitive and neural processing of images of artificial faces compared to photographs of real faces. Composites created by the computer (Carlson et al., 2012), or by other means in the days before personal computers (Ellis, Davies, \& Shepherd, 1978), seem to be recognized and remembered less than photos of real faces, which has practical (police and forensic) implications. Some studies have also observed differences in the recognition of emotions from images of artificial versus real faces (Ehrlich et al., 2000; Kätsyri \& Sams, 2008). At the neural level, the event-related potentials (ERP) triggered by artificial and real faces expressing happiness, anger, fear, or no emotion show that early cortical processing differs in these two types of stimuli depending on the person's social-anxiety level (Mühlberger et al., 2009). Using the same technique (ERP), Wheatley et al. (2011) found that natural faces, but not artificial ones, sustain neural activity beyond the first 170 milliseconds. 
Given the processing differences found in the perception of artificial versus real faces, this study provided an opportunity to test the robustness of Author's (2015) finding, by examining the sexual attraction of artificial faces and observing whether a similar gender difference emerges with this type of stimuli. The analysis of attractiveness ratings showed that this is the case: again, we found that sexual attraction is relatively less permeable to moral factors in men, or, conversely, sexual attraction is more permeable to moral factors in women.

Similar to what was observed with photos of real people, the moral content of the sentences paired with 3D artificial face models influenced the attractiveness scores given by men and women, but this influence was stronger in women. As stated in Author (2015, p.6), "male attraction at first sight to a strange woman seemed relatively less permeable to moral factors than female attraction to a strange man", and now a similar phenomenon has been observed with artificial stimuli.

A gender difference of this nature is coherent with an evolutionary approach to human sexuality (Buss, 2007; Buss \& Schmitt, 1993; but see Eagly \& Wood, 1999), where there is a clear asymmetry in biological parental investment (internal fertilization, gestation, and lactation) between women and men. This biological asymmetry would favor an asymmetry in mating strategies: cross-cultural studies show that men, compared to women, are more willing to engage in casual sex, and they are less selective with a stranger (Clark and Hatfield's, 1989; Schützwohl et al., 2009; but see Conley, 2011), whereas women tend to be more selective. In Buss' (2007, p. 106) words, "a woman who preferred to mate with a reliable man who was willing to commit to her presumably would have had children who survived, thrived, and multiplied; over 
thousands of generations a preference for men who showed signs of being willing and able to commit evolved in women". This evolutionary view could explain a relatively greater permeability of moral factors in the sexual attraction felt by women.

\section{References}

Balas, B., \& Pacella, J. (2015). Artificial faces are harder to remember. Computers in human behavior, 52, 331-337.

Buss, D. M. (2007). The Handbook of Evolutionary Psychology. New York: Wiley.

Buss, D., \& Schmitt, D. (1993). Sexual strategies theory - an evolutionary perspective on human mating. Psychological Review, 100(2), 204-232.

Carlson, C. A., Gronlund, S. D., Weatherford, D. R., \& Carlson, M. A. (2012). Processing differences between feature-based facial composites and photos of real faces. Applied Cognitive Psychology, 26(4), 525-540.

Cohen, J. (1988). Statistical power analysis of the behavioral sciences (2nd ed.). New York: Academic Press.

Clark, R. D., \& Hatfield, E. (1989). Gender differences in receptivity to sexual offers. Journal of Psychology and Human Sexuality, 2, 39-55.

Conley, T. (2011). Perceived Proposer Personality Characteristics and Gender Differences in Acceptance of Casual Sex Offers. Journal of Personality and Social Psychology, 100(2), 309-329.

Eagly, A., \& Wood, W. (1999). The origins of sex differences in human behavior Evolved dispositions versus social roles. American Psychologist, 54(6), 408-423.

Ellis, H. D., Davies, G. M., \& Shepherd, J. W. (1978). Remembering pictures of real and 'unreal' faces: some practical and theoretical considerations. British Journal of Psychology, 69(4), 467-474.

Ehrlich, S. M., Schiano, D. J., \& Sheridan, K. (2000, April). Communicating facial affect: it's not the realism, it's the motion. In CHI'OO Extended Abstracts on Human Factors in Computing Systems (pp. 251-252). ACM. 
Author (2015). Men dissociate sexual attraction from moral judgement more than women. International Journal of Psychology (published on line first). doi: 10.1002/ijop.12228.

Furnham, A. (2009). Sex differences in mate selection preferences. Personality and Individual Differences, 47(4), 262-267. doi: 10.1016/j.paid.2009.03.013.

Gross, A., \& Crofton, C. (1977). What Is Good Is Beautiful. Sociometry, 40(1), 85-90. Hamann, S., Herman, R., Nolan, C., \& Wallen, K. (2004). Men and women differ in amygdala response to visual sexual stimuli. Nature Neuroscience, 7(4), 411-416. doi:10.1038/nn1208.

Kätsyri, J., \& Sams, M. (2008). The effect of dynamics on identifying basic emotions from synthetic and natural faces. International Journal of Human-Computer Studies, 66(4), 233-242.

Kennair, L. E. O., Schmitt, D., Fjeldavli, Y. L., Harkem, S. K. (2009). Sex Differences in Sexual Desires and Attitudes in Norwegian Samples. Interpersona, 3 (Suppl.1), 132.doi:10.5964/ijpr.v3isupp1.67.

Kniffin, K., \& Wilson, D. (2004). The effect of nonphysical traits on the perception of physical attractiveness - Three naturalistic studies. Evolution and Human Behavior, 25(2), 88-101.

Lefevre, C., Ewbank, M., Calder, A., Von dem Hagen, E., \& Perrett, D. (2013). It is all in the face: carotenoid skin coloration loses attractiveness outside the face. Biology Letters, 9(6).

Lewandowski, G., Aron, A., \& Gee, J. (2007). Personality goes a long way: The malleability of opposite-sex physical attractiveness. Personal Relationships, 14(4), 571-585.

Lippa, R. (2009). Sex Differences in Sex Drive, Sociosexuality, and Height across 53 Nations: Testing Evolutionary and Social Structural Theories. Archives of Sexual Behavior, 38(5), 631-651. doi: 10.1007/s10508-007-9242-8.

Mühlberger, A., Wieser, M. J., Herrmann, M. J., Weyers, P., Tröger, C., \& Pauli, P. (2009). Early cortical processing of natural and artificial emotional faces differs between lower and higher socially anxious persons. Journal of neural 
transmission, 116(6), 735-746.

Oosterhof, N. N., \& Todorov, A. (2008). The functional basis of face evaluation.

Proceedings of the National Academy of Sciences, 105(32), 11087-11092.

Rupp, H., \& Wallen, K. (2008). Sex differences in response to visual sexual stimuli: A review. Archives of Sexual Behavior, 37(2), 206-218. doi: 10.1007/s10508-0079217-9.

Schmitt, D. (2005). Sociosexuality from Argentina to Zimbabwe: A 48-nation study of sex, culture, and strategies of human mating. Behavioral and Brain Sciences, 28(2), 247. doi: 10.1017/S0140525X05000051.

Schmitt, D., et al., International Sexuality Description Project. (2003). Universal sex differences in the desire for sexual variety: Tests from 52 nations, 6 continents, and 13 islands. Journal of Personality and Social Psychology, 85(1), 85-104. doi: 10.1037/0022-3514.85.1.85.

Schutzwohl, A., Fuchs, A., McKibbin, W., \& Shackelford, T. (2009). How Willing Are You to Accept Sexual Requests from Slightly Unattractive to Exceptionally Attractive Imagined Requestors? Human Nature-an Interdisciplinary Biosocial Perspective, 20(3), 282-293.

Science (2015). Estimating the reproducibility of psychological science. Science, 349(6251). doi: 10.1126/science.aac4716.

Singular Inversions. (2010). FaceGen Modeller, Version 3.5. www.facegen.com.

Swiderska, A., Krumhuber, E. G., \& Kappas, A. (2013). When humans become objects: Out-group effects in real and artificial faces. Proceedings of the 5th Humaine Association Conference on Affective Computing and Intelligent Interaction (ACII) (pp.612-617). doi: 10.1109/ACII.2013.107.

Wheatley, T., Weinberg, A., Looser, C., Moran, T., \& Hajcak, G. (2011). Mind perception: Real but not artificial faces sustain neural activity beyond the N170/VPP. PloS one, 6(3), e17960.

Zhang, Y., Kong, F., Zhong, Y., \& Kou, H. (2014). Personality manipulations: Do they modulate facial attractiveness ratings? Personality and Individual Differences, 70 , 80-84. 
Notes

1 Moral content of the "good" and "bad" sentences used in Autor (2015) was tested in that study. A sample of participants rated the moral valence of each sentence, and data confirmed that "good" sentences obtained a much higher score than "bad" sentences.

${ }^{2}$ Partial eta-squared $\left(\eta^{2} p\right)$ is an effect size measure in ANOVA. It refers to the proportion of variability in the dependent variable that is attributable to a factor. The effect size interpretations for $\eta_{p}^{2}$ values are as follows: $.01=$ small, $.06=$ medium and $.14=$ large (Cohen, 1988).

\section{Acknowledgments}

This work was supported by the Spanish Ministry of Economy and Competitiveness (Research Grant FFI2014-54088-P). 
Table 1. Means, standard deviations (SD), and $95 \% \mathrm{Cl}$ of attractiveness ratings of artificial face models by men and women according to the moral type of the sentences accompanying the models ("good" vs. "bad").

\begin{tabular}{cccccccccc}
\hline & \multicolumn{3}{c}{ "Good" sentences } & & \multicolumn{3}{c}{ "Bad" sentences } \\
& Mean & SD & $95 \% \mathrm{Cl}$ & & & Mean & SD & $95 \% \mathrm{Cl}$ \\
\cline { 2 - 3 } male participants $(\mathrm{n}=27)$ & 3.03 & 0.63 & $(2.78-3.28)$ & & 2.70 & 0.67 & $(2.44-2.97)$ \\
female participants $(\mathrm{n}=61)$ & 2.84 & 0.77 & $(2.64-3.04)$ & & 2.09 & 0.66 & $(1.92-2.26)$ \\
\hline
\end{tabular}


Table 2. Significant effects (ANOVA) and effect sizes ${ }^{2}$

\begin{tabular}{|c|c|c|c|c|c|c|c|c|}
\hline & \multicolumn{4}{|c|}{ Through subjects } & \multicolumn{4}{|c|}{ Through items } \\
\hline & $F_{1}$ & $d f$ & $p$ & $\eta_{p}^{2}$ & $F_{2}$ & $d f$ & $p$ & $\eta_{p}^{2}$ \\
\hline Sentence's Moral Type & 43.65 & 1,86 & $<.001$ & .34 & 98.69 & 1,39 & $<.001$ & .72 \\
\hline Participant Gender & 8.39 & 1,86 & $<.01$ & .08 & 8.56 & 1,39 & $<.01$ & .18 \\
\hline Moral Type x P. Gender & 6.43 & 1,86 & .013 & .07 & 17.29 & 1,39 & $<.001$ & .31 \\
\hline
\end{tabular}


Figure 1. Examples of two artificial faces created with the FaceGen software and used as experimental stimuli. Each face was paired with a "good" sentence (e.g., s/he is a defender of human rights in an NGO) and a "bad" sentence (e.g., s/he belongs to a terrorist group).

(Note: please, reproduce Figure 1 in $\mathrm{B} \& \mathrm{~W}$ in the print version)
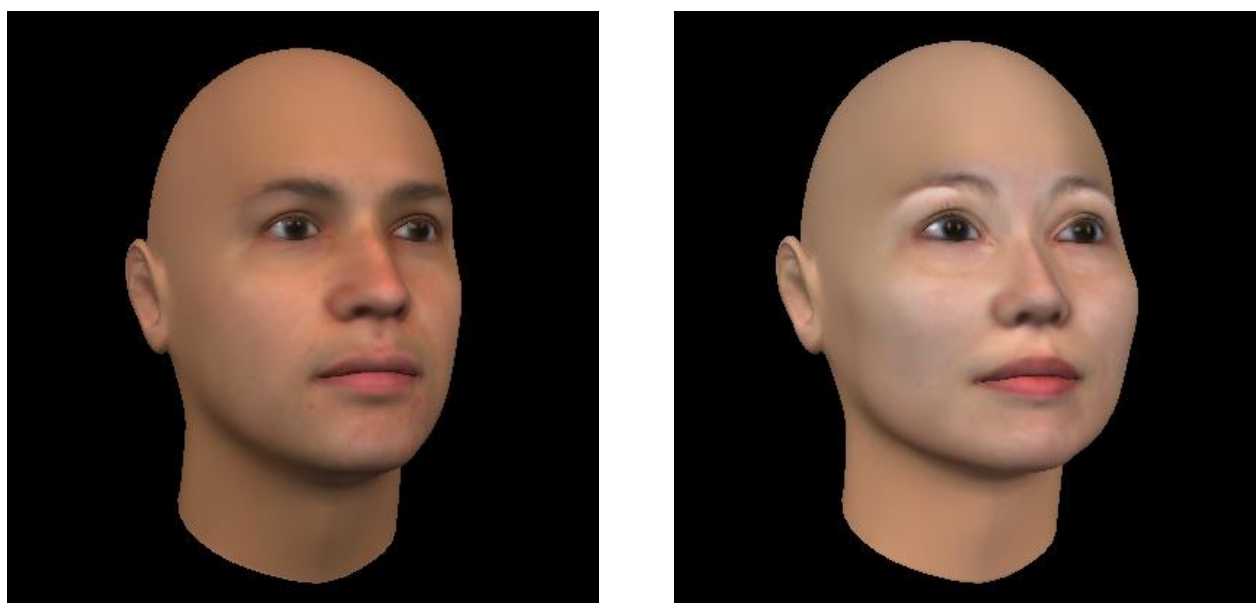
Figure 2. Example of an artificial face created with the FaceGen software and used as filler stimuli. This face was paired with the sentence "Angela Merkel is the current head of government of Germany since 2005".

(Note: please, reproduce Figure 2 in $\mathrm{B} \& \mathrm{~W}$ in the print version)

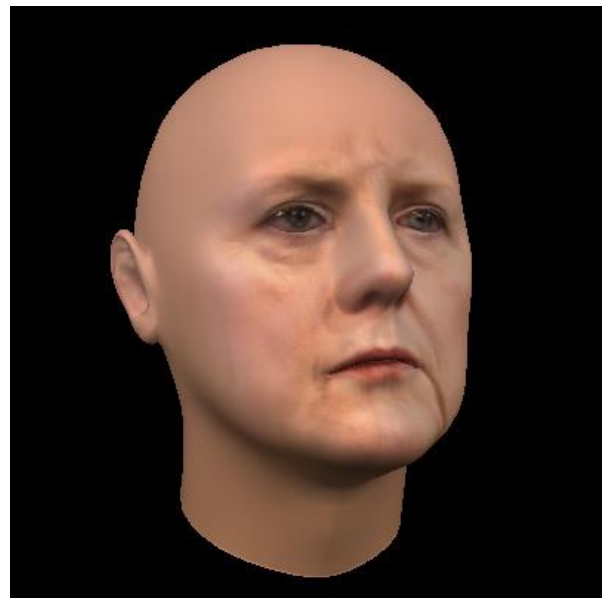

